\title{
KAMPANYE CEGAH STUNTING, BANGSA SEHAT SEJAHTERA
}

\section{Tri Siswati ${ }^{1}$ dan Yustiana Olfah ${ }^{2}$}

\author{
${ }^{1}$ Poltekkes Kemenkes Yogyakarta \\ Email: trisiswati14@gmail.com, \\ ${ }^{2}$ Poltekkes Kemenkes Yogyakarta \\ Email: yustianajogja@gmail.com
}

\begin{abstract}
According to Riskesdas 2018, 3 out of 10 toddlers suffer from stunting. Stunting in early life tends to settle into stunting in later life periods in childhood, adolescence, adulthood and the elderly. Stunting has short-term consequences in the form of low learning achievement and reduced opportunities to get a good school. In the long term, stunting causes a $22 \%$ reduction in the chance of getting good jobs compared to normal adults and has the potential to suffer from metabolic syndrome is higher than normal adults. While short adolescents will grow into short WUS with all the consequences including giving birth to low birth weight babies and short, and the risk of giving birth with Secsio Caesar (SC) is higher because of "chepalo-pelvic disproportion". On one side of the SC is the high risk of failure to initiate early breastfeeding (IMD) and exclusive breastfeeding, even though breast milk is very important for child development and development including preventing stunting. The stunting prevention campaign which was held on December 14th at GOR Amongrogo Yogyakarta, was carried out in collaboration with the Presidential Staff Office (KSP), the Yogyakarta Health Office, Yogyakarta Health Polytechnic, CIMSA (the center of medical student activities throughout Indonesia) and NA (Nasyiatul Aisyiyah), presenting approximately 500 participants to participate in campaign activities to prevent stunting. In this activity it was reported as many as $20.6 \%$ of overweight and obese adolescents, and $26.3 \%$ of adolescents stunted $29.8 \%$ of KEK adolescents and there were still many adolescents who were out of balance to achieve their desired body image. While overweight-obese in adults as much as $69.4 \%$, short $26.7 \%$ and hypertension-hypertension $35.9 \%$. In addition to anthropometric measurements, counseling was also held regarding reproductive health, mental health, food consumption and nutritional status.
\end{abstract}

Keywords: stunting; teenager; anthropometry; campaign

\begin{abstract}
ABSTRAK
Menurut Riskesdas 2018, 3 dari 10 balita menderita stunting. Stunting pada awal kehidupan cenderung menetap menjadi stunting pada periode kehidupan selanjutnya baik pada masa kanak-kanak, remaja, dewasa dan lansia. Stunting membawa konsekuensi jangka pendek berupa prestasi belajar yang rendah serta berkurangnya kesempatan untuk mendapatkan sekolah yang baik. Pada jangka panjang, stunting menyebabkan berkurangnya $22 \%$ peluang untuk mendapatkan lapangan pekerjaan yang baik dibandingkan dewasa yang normal serta berpotensi menderita sindrom metabolic lebih tinggi dibanding dewasa normal. Sementara remaja yang pendek akan tumbuh menjadi WUS yang pendek dengan segala konsekuensinya termasuk melahirkan bayi BBLR dan pendek, serta risiko melahirkan dengan Secsio Caesar (SC) lebih tinggi karena "chepalo-pelvic disproportion". Disatu sisi SC adalah risiko tingginya kegagalan inisiasi menyusu dini (IMD) dan ASI eksklusif, padahal ASI sangat penting bagi tumbuh kembang anak termasuk mencegah stunting. Kampanye cegah stunting yang diselenggarakan pada tanggal 14 Desember di GOR Amongrogo Yogyakarta, dilakukan atas kerjasama dengan Kantor Staf Kepresidenan (KSP), Dinkes DI Yogyakarta, Poltekkes Kemenkes Yogyakarta, CIMSA (pusat kegiatan mahasiswa kedokteran se-Indonesia) dan NA (Nasyiatul Aisyiyah), menghadirkan kurang lebih 500 peserta untuk berpartisipasi dalam kegiatan kampanye cegah stunting. Pada kegiatan ini dilaporkan sebanyak 20,6\% remaja overweight dan obese, dan $26,3 \%$ remaja mengalami stunting 29,8\% remaja KEK serta masih banyak remaja yang diit tidak seimbang untuk mencapai body image yang mereka idam-idamkan. Sementara overweight-obese pada dewasa sebanyak 69,4\%, pendek 26,7\% dan prehipertensi-hipertensi 35,9\%. Selain pengukuran antropometri, diadakan pula konseling mengenai kesehatan reproduksi, kesehatan mental, konsumsi makan dan status gizi.
\end{abstract}

Kata kunci: stunting; remaja; antropometri; kampanye

\section{PENDAHULUAN}

Stunting adalah pendek menurut umur yang disebabkan oleh kekurangan gizi kronis dan infeksi berulang-ulang selama masa 1000 hari pertama kehidupan (WHO, 2014; WHO, 2015). Berdasarkan WHO antropometri 2005, balita dikatakan stunting apabila nilai indeks tinggi badan menurut umur (TB/U) kurang dari -2 standar deviasi (Blössner et al., 2005). Stunting menjadi masalah global yang sangat serius di seluruh dunia. Menurut WHO, 2018 sebanyak 151 juta 
$(22,2 \%)$ balita menderita stunting. Jumlah masalah gizi ini paling tinggi dibandingkan jumlah balita yang menderita obese/kegemukan dan wasting/kurus, yakni masing-masing sebesar 38 juta $(38,5 \%)$ dan 51 juta $(7,5 \%)$ balita di seluruh dunia. Di Indonesia berdasarkan Riskesdas 2007, 2010, 2013 dan 2018 prevalensi stunting balita dilaporkan masing-masing sebanyak 36,8\%; 35,6\%; 37,2\% dan 30,8\%. Menurut WHO 2005 prevalensi stunting ini kategori masalah stunting berat, yakni diatas 30\% (WHO, 2005). Stunting dini cenderung relative tetap stunting pada periode usia kehidupan berikutnya. Menurut Aryastami 2015, kurang dari 30\% balita stunting yang berhasil re-cacth up menjadi normal pada usia remaja.

Penurunan stunting $40 \%$ menjadi salah satu target pembangunan berkelanjutan/Sustainable Development Goals (SDG's) yang secara global akan dicapai oleh seluruh negara-negara di dunia pada tahun 2025 (WHO, 2012). Dengan kebijakan ini, maka target prevalensi stunting balita di Indonesia pada tahun 2025 adalah 14,9\%. Stunting menyebabkan kegagalan fetal programming sehingga respon tubuh terhadap sindrom metabolik lebih besar, risiko obesitas lebih tinggi (Barker, 1997; Muragee et al., 2005), metabolisme rate dan lemak oksidatif yang lebih rendah (Hoffman et al., 2000), resistensi insulin dan penyakit-penyakit sindrom metabolik lainnya (Mardones et al., 2014). Penelitian kohort di Brazil menyatakan bahwa anak yang stunting mempunyai kadar $H D L$ yang rendah, kadar glukosa, trigliserid, tekanan darah yang tinggi, lingkar pinggang yang lebar, serta mengalami overweight dan obesitas dibanding anak-anak yang tidak stunting (Grillo, et al., 2016). Sayangnya berdasarkan studi kualitatif pada masyarakat pengetahuan dan kesadaran masyarakat mengenai stunting masih kurang. Mereka beranggapan bahwa stunting bukan masalah yang serius karena secara fisik anak stunting sehat hanya perawakannya yang pendek.

Remaja merupakan usia periode emas, mereka masih mempunyai banyak kesempatan untuk memperbaiki dan meningkatkan derajat kesehatan termasuk upaya memperbaiki status gizi bagi dirinya sendiri maupun generasi mendatang. Untuk remaja putri khususnya, stunting bisa dieradikasi dengan optimal,karena mereka adalah calon ibu yang akan melahirkan generasi mendatang. Menurut Harding 2001, diperlukan 2 generasi untuk mengentaskan masalah stunting balita, bahkan hingga 12 generasi (Stewart, et al., 1980). Dalam rangka mengkampanyekan pentingnya pencegahan stunting, KSP (Kantor Staf Kepresidenan) bersama-sama dengan Dinas Kesehatan propinsi DIY, Poltekkes Kemenkes Yogyakarta, Nahdatul Aisyah (NA), dan Center of Indonesia Medical Student Activity (CIMSA) menggelar acara stand Nutrition Center pada kegiatan Kampanye Stunting di GOR Amongrogo, Yogyakarta tanggal 14 Desember 2018. Stand ini bertujuan untuk menganamesis kondisi gizi client dan memberikan konsultasi sesuai dengan hasil anamnesis. Layanan yang diberikan berupa Posbindu dan Posyandu remaja meliputi pendaftaran, pengukuran (antropometri dan tekanan darah), pencatatan, pelayanan konsultasi (gizi, kesehatan dan kesehatan reproduksi) diberikan secara cuma cuma.

\section{HASIL KEGIATAN}

Stand Nutrition Center dilaksanakan pada hari Jumat, 14 Desember 2018 mulai pukul 8.30 hingga 11.00. Sebanyak 156 orang berbagai usia berkunjung pada stand ini. Sebanyak 10 mahasiswa yang tergabung dalam CIMSA, 12 mahasiswa Poltekkes Kemenkes Yogyakarta, dan 2 orang dari NA memberikan pelayanan kesehatan secara professional bagi para pengunjung baik remaja maupun dewasa. Karakteristik dan hasil anamnesis kondisi gizi dan kesehatan pengunjung dilaporkan secara detail.

1. Karakteristik Klien

a. Usia dan jenis kelamin

Sebagian besar klien adalah perempuan (Gambar 1 dan Gambar 2). 


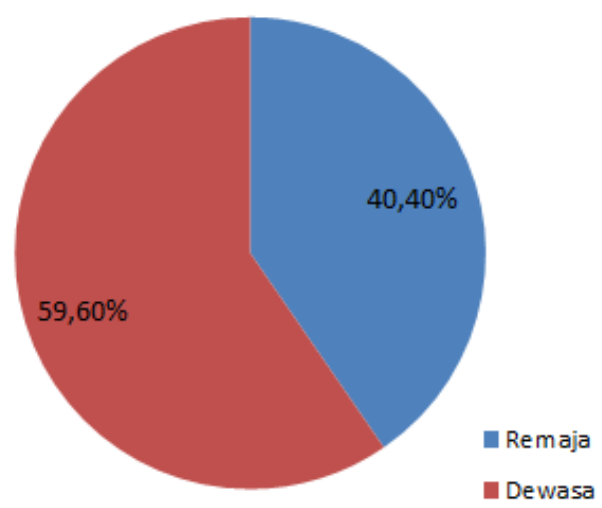

Gambar 1. Karakteristik Klien Berdasarkan Usia

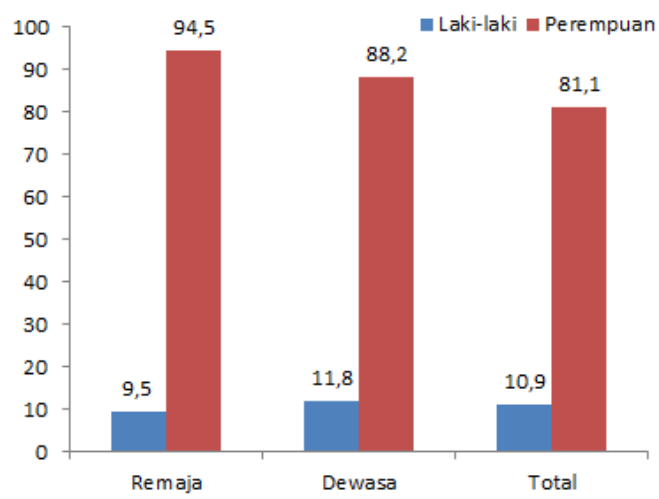

Gambar 2. Karakteristik Klien Berdasarkan Jenis Kelamin

2. Hasil anamnesis kondisi gizi dan kesehatan pengunjung.

a. Status gizi berdasarkan IMT

Hasil pengukuran IMT dikategorikan berdasarkan Center for obesity research and education, 2007.

Tabel 1. Kategori status gizi berdasarkan IMT

\begin{tabular}{|l|l|l|}
\hline Indikator & Kategori* & Batasan \\
\hline IMT & Berat badan kurang & $<18,5$ \\
\hline & Normal & $18,5-22,9$ \\
\hline & Berisiko obese & $23,0-24,9$ \\
\hline & Obese I & $25,0-29,9$ \\
\hline & Obese II & $\geq 30$ \\
\hline
\end{tabular}

Ket : * Center for obesity research and education, 2007

Berdasarkan kategori tersebut, jumlah klien yang mempunyai status gizi normal dan risiko obese/obese hampir sama (Gambar 3). 


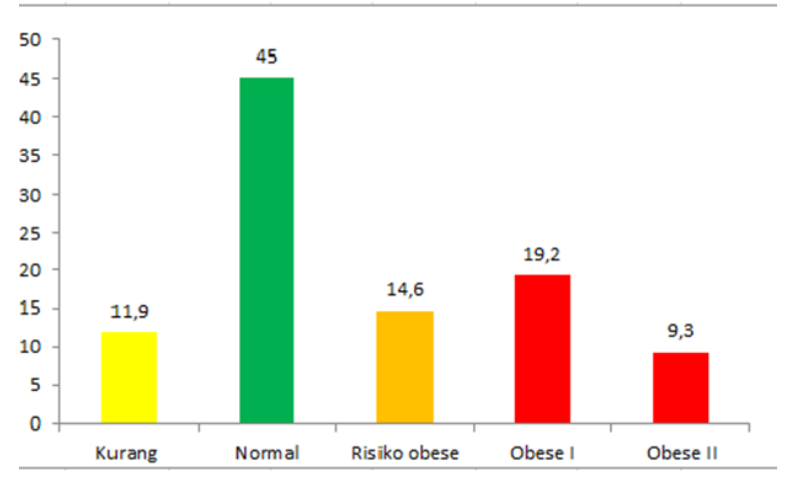

Gambar 3. Karakteristik Klien Berdasarkan IMT

Selanjutnya hasil pengukuran dibedakan pada remaja dan dewasa, laki-laki dan perempuan karena besarnya faktor risiko dan intervensinya berbeda.

\section{Klien Remaja}

Sebagian besar remaja mempunyai status gizi normal, namun hampir seperempatnya berisiko obese dan obese (Gambar 4). Obese baik obese derajat 1 maupun 2 ditemukan pada remaja perempuan (Gambar 5).

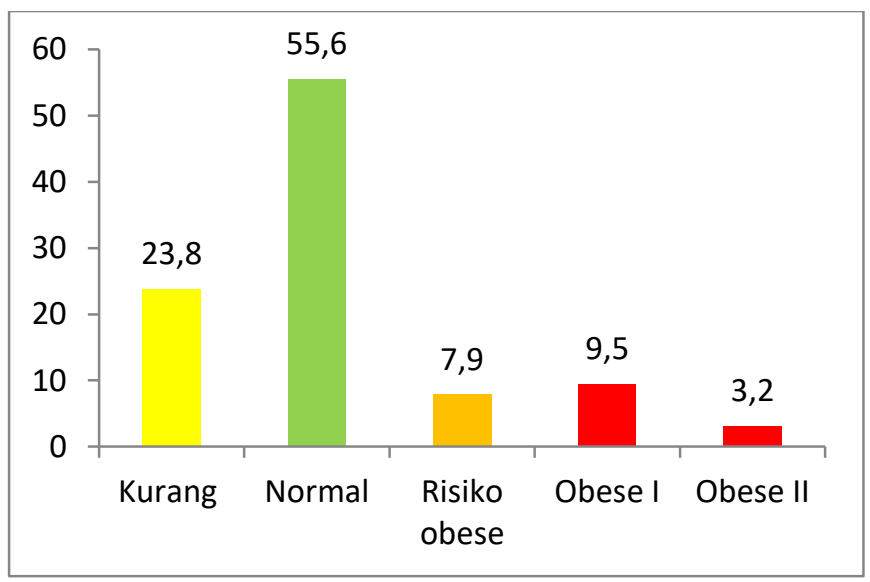

Gambar 4. Karakteristik Remaja Berdasarkan IMT

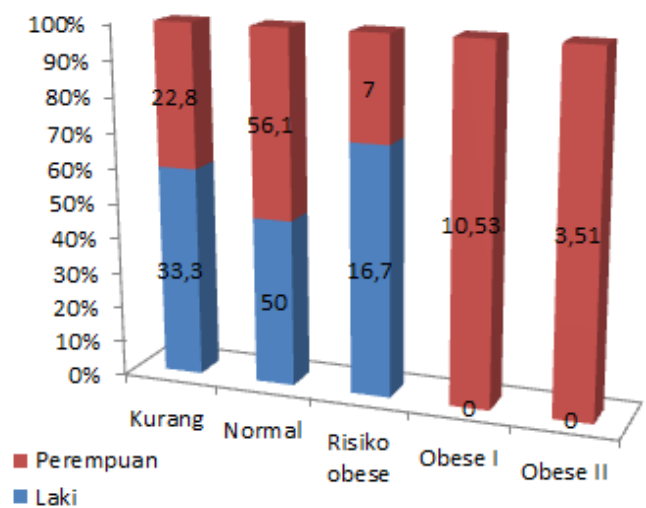

Gambar 5. Karakteristik Remaja Berdasarkan IMT dan Jenis Kelamin 


\section{Klien Dewasa}

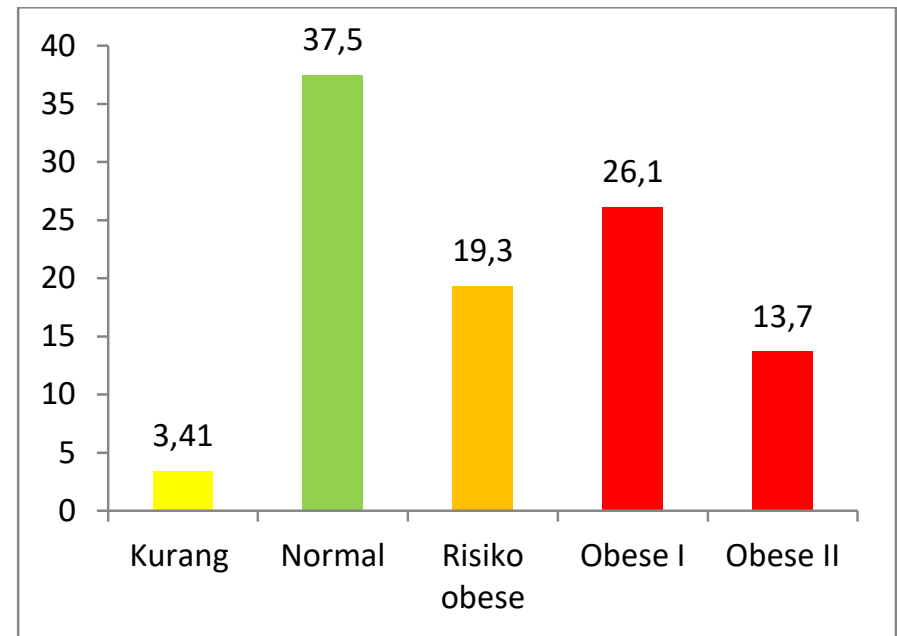

Gambar 6. Karakteristik Klien Dewasa Berdasarkan IMT

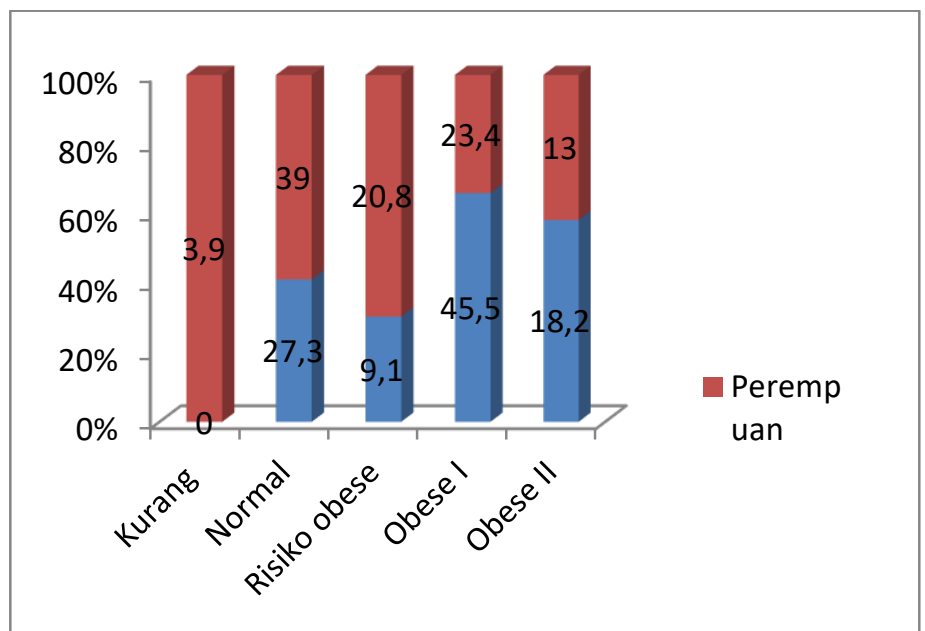

Gambar 7. Karakteristik Klien Dewasa Berdasarkan IMT, Kelompok Umur dan Jenis Kelamin

b. Status gizi berdasarkan tinggi badan

Remaja

Status gizi berdasarkan indeks tinggi badan menurut umur, dikaterogikan menjadi stunting bila $\mathrm{TB} / \mathrm{U}<-2 \mathrm{SD}$ dan normal bila TB/U $\geq-2$ SD (WHO, 2005). Hasil pengukuran status gizi menurut TB/U menunjukkan bahwa 3 dari 10 remaja putri menderita stunting (Gambar 8).

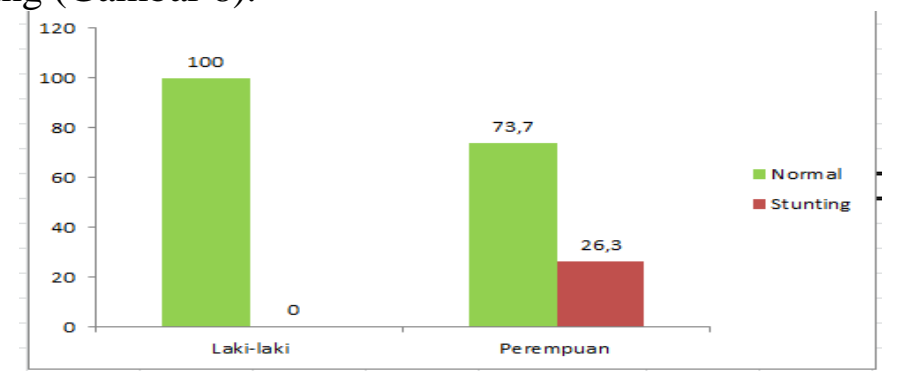

Gambar 8. Status Gizi Remaja Berdasarkan TB/U dan Jenis Kelamin 


\section{Dewasa}

Tinggi badan usia dewasa dibedakan menjadi normal dan pendek. Cut off untuk tinggi badan usia dewasa bagi wanita adalah $\geq 150 \mathrm{~cm}$, dan pria $\geq 160 \mathrm{~cm}$. Hasil pengukuran tinggi badan dewasa menunjukkan bahwa proporsi pendek pada perempuan dewasa 3 kali lebih banyak dibanding laki-laki, secara detail pada Gambar 9.

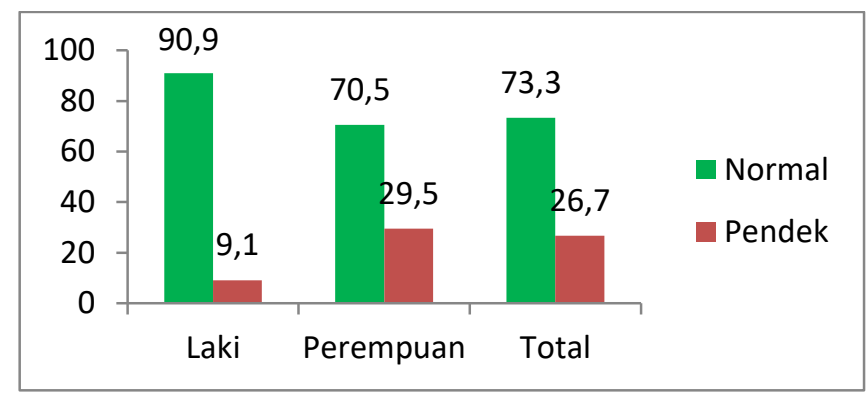

Gambar 9. Tinggi Badan Dewasa

c. Status gizi perempuan berdasarkan LILA

Pengukuran status gizi berdasarkan LILA menggunakan cut off 23,5 Cm. Wanita dinyatakan KEK bila LILA $\quad<23,5 \mathrm{~cm}$. Hasil pengukuran menyatakan bahwa 3 dari 10 remaja menderika KEK. Secara detail pada Gambar 10.

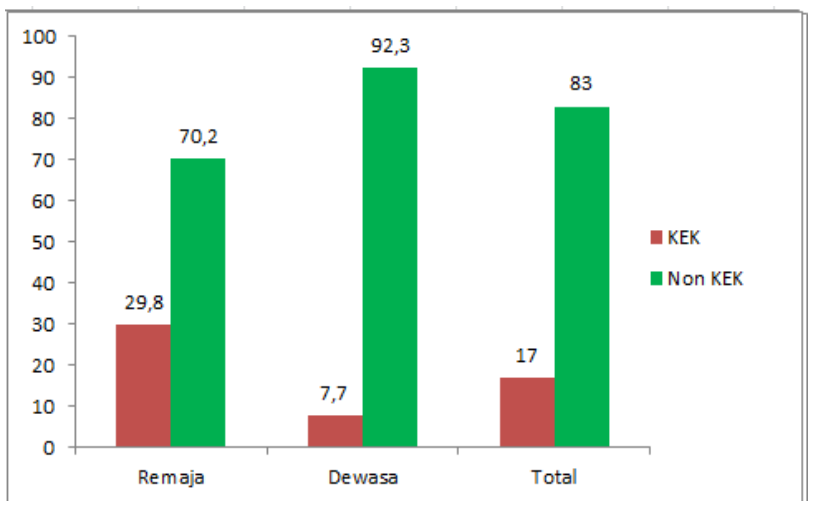

Gambar 10. Status Gizi Wanita Berdasarkan LILA

d. Status hipertensi

Sebanyak 64 klien $(41 \%)$ diukur tekanan darahnya. Hasil pengukuran tekanan darah dikategorikan pada tabel 2 .

Tabel 2. Kategori hipertensi

\begin{tabular}{|l|c|c|c|}
\hline \multicolumn{1}{|c|}{ Kategori } & Sistol $\mathbf{( m m H g )}$ & Ket & Diastol $\mathbf{( m m H g )}$ \\
\hline Normal & $<120$ & Dan & $<80$ \\
\hline Pre hipertensi & $120-129$ & Dan & $<80$ \\
\hline Hipertensi I & $130-139$ & Atau & $80-89$ \\
\hline Hipertensi II & 140 atau lebih & Atau & 90 atau lebih \\
\hline Krisis & Diatas 180 & Dan atau & Lebih dari 120 \\
\hline
\end{tabular}

Sumber : American Hearth Association 
Berdasarkan kategori tersebut, 4 dari 10 klient perlu mendapatkan pencegahan sekunder dan tersier sehingga tidak terjadi akibat lanjut dari hipertensi (Gambar 11)

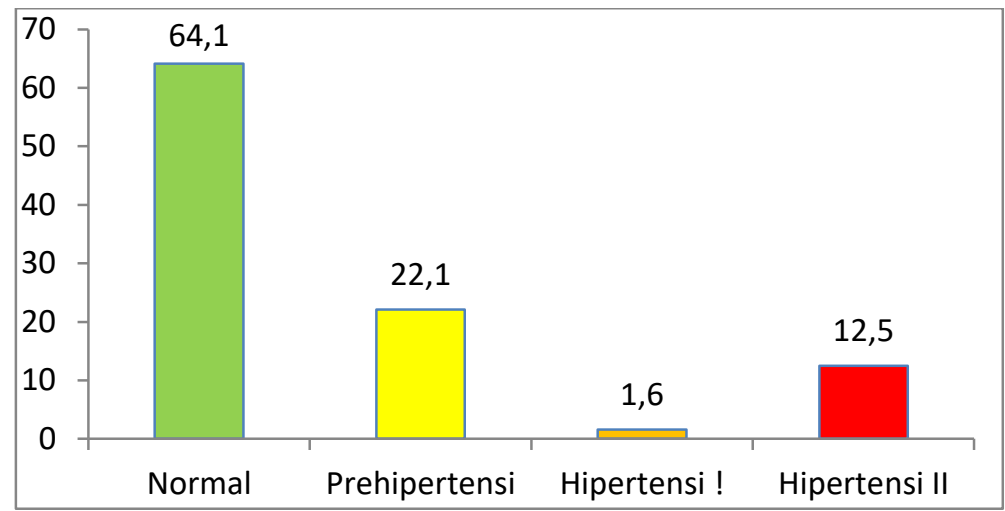

Gambar 11. Hasil pengukuran tekanan darah klient

\section{KESIMPULAN DAN SARAN}

Pada hasil pengukuran 3 dari 10 remaja putri menderita stunting. Remaja putri akan tumbuh menjadi wanita dewasa, menikah, hamil dan peluang melahirkan stunting intergenerasi. Stunting intergenerasi sangat dekat dengan kemiskinan intergenerasi. Sementara pada dewasa, 3 dari 10 dewasa menderita stunting. Sindrom metabolic yang ditemukan adalah overweight/obese dan prehipertensi/hipertensi. Rekomendasi pengentasan stunting pada remaja adalah memberikan edukasi tentang pentingnya kesehatan serta menjadikan pendidikan sebagai cara pengentasan masalah stunting. Pendidikan tinggi menghindari perkawinan dini, melahirkan di usia belia, potensi mendapatkan pasangan yang tingkat pendidikannya relative setara tinggi, peluang mendapat pekerjaan mapan semakin besar, sehingga permasalahan malnutrisi dapat diatasi. Sementara pada dewasa, perlu melakukan Germas seperti pola hidup sehat, konsumsi gizi seimbang, melakukan aktifitas fisik, kelola stress dan pemeriksaan berkala 1 bulan sekali melalui Posbindu/pelayanan lainnya untuk mencegah timbulnya komplikasi

\section{REFERENSI}

Aryastami, N.K., Secondary, C.A., Shankar, A., Kusumawardani, N., 2017. Nutrition low birth weight was the most dominant predictor associated with stunting among children aged 1223 months in Indonesia. BMC Nutr. 1-6.

Badan Penelitian dan Pengembangan Kesehatan, Kemenkes RI, 2007. Riset Kesehatan Dasar (RISKESDAS), Jakarta.

Badan Penelitian dan Pengembangan Kesehatan, Kemenkes RI, 2010. Riset Kesehatan Dasar (RISKESDAS), Jakarta.

Badan Penelitian dan Pengembangan Kesehatan, Kemenkes RI 2013. Riset Kesehatan Dasar (RISKESDAS), Jakarta

Badan Penelitian dan Pengembangan Kesehatan, Kemenkes RI 2018. Hasil Riset

Kesehatan Dasar (RISKESDAS), Jakarta

Barker, D.J., Clark, P.M., 1997. Fetal undernutrition and disease in later life. Rev. Reprod. 2, 105-12.

Blössner, M., Borghi, E., Onis, M. de, Onyango, A., Siyam, A., Yang, H., 2005.WHO Anthro 2005 for Personal Computers.

Grillo, L.P., Gigante, D.P.,Horta, B.L., Barros,C.F.C., 2016.,Childhood stunting and the metabolic syndrome components in young adults from a Brazilian birth cohort study. Eur J Clin Nut.70, 548-553 
Harding, J., 2001. The nutritional basis of the fetal origins of adult disease. Int. J. Epidemiol. 30, $15-23$.

Harding J. 2004.Nutritional basis for the fetal originsof adult diseases (in) Fetal nutrition and adult disease: programming of chronic disease through fetal exposure to undernutrition. Langley-Evans S, editor. Oxfordshire, UK:CABI Publishing.

Hoffman, D.J., Sawaya, A.L., Verreschi. I, Tucker, K.L, Roberts, S.B, 2000. Why are nutritionally stunted children at increased risk of obesity? Studies of metabolic rate and fat oxidation in shantytown children from São Paulo, Brazil._Am J Clin Nutr. 72(3):702-7.

Murage, E.W.K., Kahn, K., Pettifor, J.M.,Tollman, S.M., Dunger, D.B., Olivé, X.F.G., Norris,S.A., 2010. The prevalence of stunting, overweight and obesity, and metabolic disease risk in rural South African children. BMC Public Health. 10:158. pp 1-13

Mardones, F., Arnaiz, P., Pacheco, P., Dominguez. A., Villarroel, L., Eriksson, J.G., Barja, S., Farías, M., Castillo, O.,2014. Associations of prenatal growth with metabolic syndrome, insulin resistance, and nutritional status in Chilean Children. Biomed Res. Int.pp1-9

WHO,2005. Commission on Social Determinants of Health, 2005-2008. http://www.who.int/social_determinants/thecommission/en/

WHO,2014.Global Nutrition Targets 2025Stunting Policy Brief. Available at http://apps.who.int/WHO_NMH_NHD_14.3_eng.pdf. diunduh pada 23 Februari 2019

WHO 2018, Joint child malnutrition estimates - Levels and trends (2018 edition), available at https://www.who.int/nutgrowthdb/estimates2017/en/ 